\title{
Congenital subclavian-superior vena cava arteriovenous fistula with initial stenosis in an adult: a case report
}

\author{
Geng $\mathrm{Li}^{\dagger}$, Xingjian $\mathrm{Hu}^{\dagger}$, Yin Wang ${ }^{*}$ (1) and Si Chen ${ }^{*}$
}

\begin{abstract}
Background: A subclavian-superior vena cava arteriovenous fistula is usually acquired and secondary to trauma or operations, while congenital causes are very rare. A congenital arteriovenous fistula leads to congestive heart failure soon after birth and is typically diagnosed in early infancy.

Case presentation: We present an unusual case of a 21-year-old female suffering from new-onset heart failure at 20 years old who was diagnosed with a congenital arteriovenous fistula from the right subclavian artery to the superior vena cava (RSA-to-SVC) with stenosis at the proximal initial site of the fistula. The patient successfully underwent transcatheter occlusion for the fistula and had a significant improvement in symptoms at the 3-month follow-up.

Conclusions: An RSA-to-SVC fistula is a very rare congenital disorder that can lead to shunt-related heart failure. If there is an indication for closure, as with the patient presented, percutaneous device closure can be considered a reasonable option.
\end{abstract}

Keywords: Congenital arteriovenous fistula, Fistula stenosis, Adult, Case report

\section{Background}

Arteriovenous fistulas involving the subclavian artery and vein are uncommon in adults. They are usually acquired secondary to trauma or operations, while congenital causes are very rare [1]. Here, we present an unusual case of an adult patient suffering from newonset congestive heart failure at 20 years old who was finally diagnosed with a congenital arteriovenous fistula from the right subclavian artery (RSA) to the superior vena cava (SVC) along with stenosis at the proximal initial site of the fistula, and the "proximal initial site" was the fistula entrance near the RSA.

\footnotetext{
* Correspondence: yinwang2013@hust.edu.cn; Sichen@hust.edu.cn ${ }^{\dagger}$ Geng Li and Xingjian Hu contributed equally to this work. Department of Cardiovascular Surgery, Union Hospital, Tongji Medical College, Huazhong University of Science and Technology, Jiefang Avenue 1277\#, Wuhan 430022, P.R. China
}

\section{Case presentation}

A 21-year-old girl complaining of a six-month history of progressive dyspnoea and chest pain was transferred to our centre because of heart failure, without a history of any cardiovascular diseases, injuries or operations.

On examination, there was a grade $3 / 6$ continuous machinery murmur that was maximal between the right 2nd and 3rd intercostal region and radiated to the right infraclavicular fossa. The patient had a normal saturation value at rest in ambient air (SPO2 95\%) with noncyanotic skin colour. Chest-X-ray revealed cardiomegaly. The electrocardiogram showed sinus rhythm with a heart rate of $95 \mathrm{bpm}$ and a complete right bundle branch block and right ventricular hypertrophy. The respiratory tests were not abnormal.

Transthoracic echocardiography showed a dilated right subclavian artery with an 8-mm fistula to the SVC and obvious stenosis at the proximal initial site of the fistula, in addition to a markedly dilated right ventricle and

(c) The Author(s). 2020 Open Access This article is licensed under a Creative Commons Attribution 4.0 International License, which permits use, sharing, adaptation, distribution and reproduction in any medium or format, as long as you give appropriate credit to the original author(s) and the source, provide a link to the Creative Commons licence, and indicate if changes were made. The images or other third party material in this article are included in the article's Creative Commons licence, unless indicated otherwise in a credit line to the material. If material is not included in the article's Creative Commons licence and your intended use is not permitted by statutory regulation or exceeds the permitted use, you will need to obtain permission directly from the copyright holder. To view a copy of this licence, visit http://creativecommons.org/licenses/by/4.0/ The Creative Commons Public Domain Dedication waiver (http://creativecommons.org/publicdomain/zero/1.0/) applies to the data made available in this article, unless otherwise stated in a credit line to the data. 
right atrium and mild tricuspid regurgitation (Fig. 1a). Continuous wave Doppler showed a flow signal at 2.3 $\mathrm{m} / \mathrm{s}$ that was continuously moving from the RSA to the SVC with a gradient of $22 \mathrm{mmHg}$, while the highest flow rate was $3.9 \mathrm{~m} / \mathrm{s}$ at the stenosis site of the fistula with a gradient of $59 \mathrm{mmHg}$ (Fig. 1b). Computed tomography angiography further delineated the anatomy of the arteriovenous fistula from the RSA to the SVC and stenosis of the fistula (Fig. 1c, d).

The patient underwent transcatheter occlusion for the fistula under local anaesthesia. Briefly, a $10 / 12 \mathrm{~mm}$ Amplatzer ductal occluder was delivered and deployed from the SVC side using a 5-F H1 catheter by angiogram guidance, and an $8 \mathrm{~F}$ sheath was used to send the occluder to occlude the abnormal fistulous connection (Fig. 1e, f and supplemental video). The post-procedure angiogram revealed a completely occluded lumen of the fistula, and the echocardiogram showed no residual shunt. The patient had an uneventful course and a significant improvement in symptoms at the 3-month follow-up.

\section{Discussion and conclusions}

Acquired arteriovenous fistulas in the thoracic cavity are more common than congenital arteriovenous fistulas. In the case described above, the patient had no history of trauma or previous surgeries, so it could be deduced that

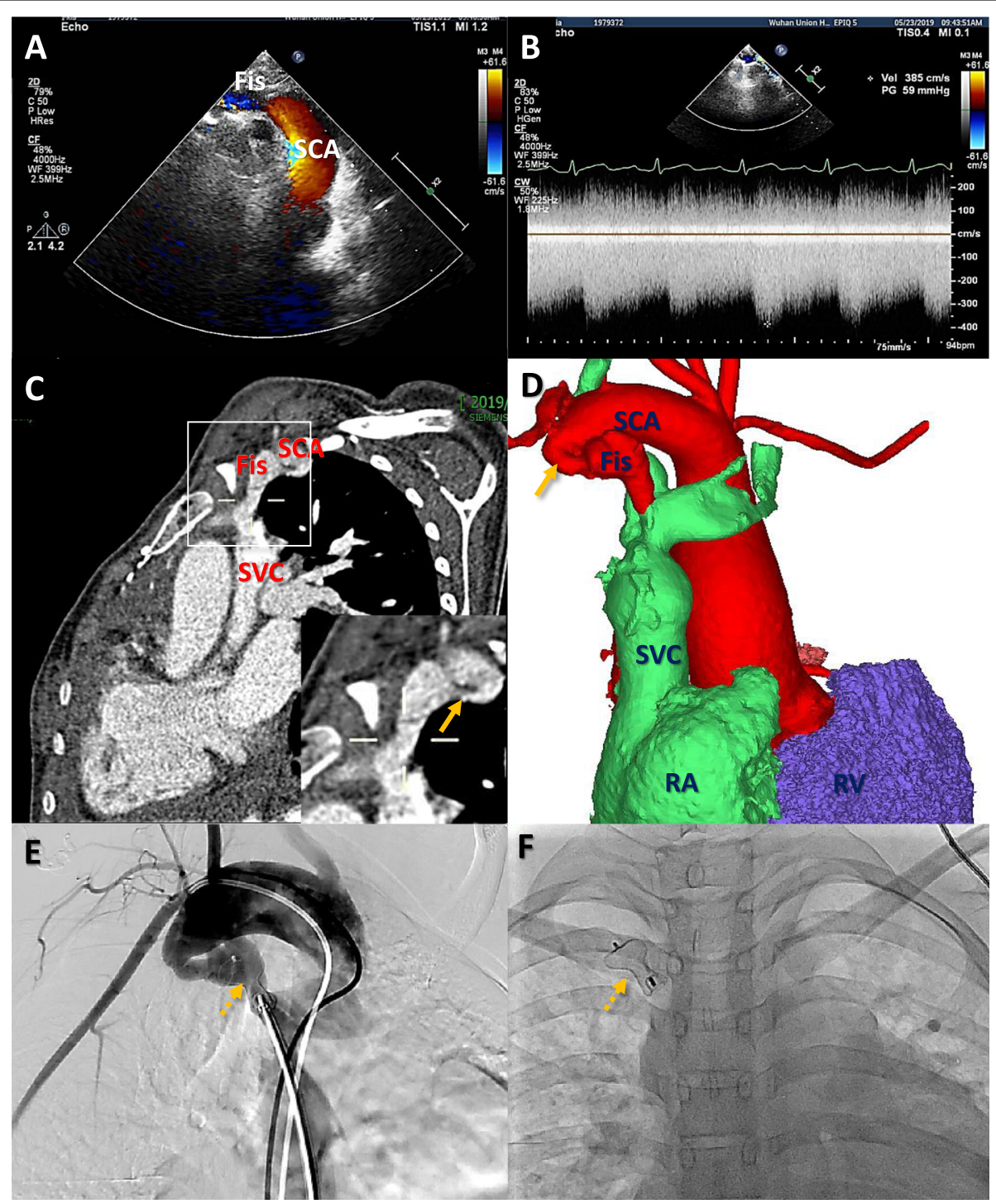

Fig. 1 a Transthoracic echocardiography shows the arteriovenous fistula (Fis) between the right subclavian artery (SCA) and the superior vena cava (SVC); b Continuous-wave Color Doppler interrogation of the fistula shows high velocity flow signals moving from the SCA into the SVC throughout the cardiac cycle (stenosis site: velocity $385 \mathrm{~cm} / \mathrm{s}$, pressure gradient $59 \mathrm{mmHg}$ ); $\mathbf{c}$, d Computed tomographic angiography and threedimensional reconstruction show the fistula and obvious stenosis site (arrow); e,f The fistula is successfully closed using a 10/12 mm Amplatzer Ductal Occluder (asterisk) by the guidance of angiography (dotted arrow); RA — right atrium; RV — right ventricle 
the arteriovenous fistula was congenital in origin. Congenital arteriovenous fistulas usually form an abnormal communication between the aorta and right heart, such as in a Valsalva fistula or coronary arterial fistula [2]. However, arteriovenous fistulas from the RSA to the SVC are rare. Awasthy et al. described an unusual case of a 4-month-old infant with a congenital arteriovenous malformation between the RSA and the SVC that was associated with SVC stenosis [3]. Balakrishnan et al. reported a case of a neonate with a congenital arteriovenous fistula from the subclavian artery to the SVC that resulted in neonatal heart failure [4]. Congenital arteriovenous fistulas from the aortic branch to the SVC often lead to congestive heart failure in newborns and infants; therefore, it is always diagnosed and treated as early as possible [5].

Surprisingly, the patient in the present case was asymptomatic for nearly 20 years after her birth, while new-onset symptoms of right heart failure had only presented in the last 6 months. She was diagnosed with a large congenital arteriovenous fistula $(8 \mathrm{~mm})$ from the RSA directly to the SVC for the first time. In this case, the occurrence of congestive heart failure was delayed, and it was likely due to stenosis at the proximal initial site of the fistula, which reduced the anomalous "leftto-right" shunt from the right subclavian artery to the superior vena cava.

To our knowledge, this may not be the first human case, but it is obviously the first one in the MEDLINE database to date. RSA-to-SVC fistulas are very rare congenital disorders that can actually lead to shunt-related heart failure. If there is an indication for closure, as with the patient presented, percutaneous device closure can be considered a reasonable therapy option.

\section{Supplementary information}

Supplementary information accompanies this paper at https://doi.org/10. 1186/s12872-020-01660-5.

\section{Additional file 1: Video.}

\section{Acknowledgements}

Not applicable.

\section{Authors' contributions}

GL collected and assembled of data and write the manuscript; $\mathrm{XH}$ analyzed the data and write the manuscript; YW revised the manuscript and approve the manuscript; SC revised the manuscript. All authors have read and approved the manuscript.

\section{Funding}

This study was financially supported by National Natural Science Foundation of China (No.81700339) to G.L. The funding only provided the financial and played no role in the design of the study and collection, analysis, and interpretation of data and in writing the manuscript.
Availability of data and materials

All data generated or analyzed during this study are included in this published article and its supplementary information files.

Ethics approval and consent to participate

This study was approved by the Ethical Committee of Tongji Medical College affiliated with Huazhong University of Science and Technology (02/08/2019 S031). The consent of patient has been obtained and the informed consent obtained was written.

\section{Consent for publication}

Written informed consent for publication was obtained from the participants Copy of the written consent is available for review by the editor of this journal.

\section{Competing interests}

The authors declare that they have no competing interests.

Received: 25 March 2020 Accepted: 9 August 2020

Published online: 17 August 2020

References

1. Hayward R, Swanton H, Treasure T. Acquired arteriovenous communication: Complication of cannulation of internal jugular vein. Br Med J (Clin Res Ed). 1984;288:1195-6.

2. Rutherford RB. Noninvasive evaluation for congenital arteriovenous fistulas and malformations. Semin Vasc Surg. 2012;25:49-57.

3. Awasthy N, Tomar M, Radhakrishnan S, Kumar P. Nonsurgical management of a congenital aortocaval fistula from right subclavian artery to superior vena cava along with svc obstruction. Pediatr Cardiol. 2011;32:227-9.

4. Balakrishnan PL, Guleserian KJ, Schuster J, Blalock SE. Congenital arteriovenous malformation between the subclavian artery and superior vena cava presenting in neonatal heart failure. Pediatr Cardiol. 2011;32: 1204-6.

5. Dogan R, Yilmaz M, Ozkutlu S, Elsharshari H. Congenital subclavian artery to subclavian vein fistula presenting with congestive heart failure in an infant. Pediatr Cardiol. 2000;21:269-70.

\section{Publisher's Note}

Springer Nature remains neutral with regard to jurisdictional claims in published maps and institutional affiliations.
Ready to submit your research? Choose BMC and benefit from:
- fast, convenient online submission
- thorough peer review by experienced researchers in your field
- rapid publication on acceptance
- support for research data, including large and complex data types
- gold Open Access which fosters wider collaboration and increased citations
- maximum visibility for your research: over $100 \mathrm{M}$ website views per year
At BMC, research is always in progress.
Learn more biomedcentral.com/submission 